\title{
Effective Design and Analysis of Conformal 3D Lattice Structure
}

\author{
S.Rajkumar ${ }^{1}$,B.Rajeswari ${ }^{2}$ \\ ${ }^{1}$ P.G.Scholar, Department of Engineering Design, \\ ${ }^{2}$ Assistant Professor, Department of Mechanical Engineering, \\ Government college of Technology, Coimbatore-13, Tamilnadu - India. \\ Email: rajkumarsrk24@yahoo.com ${ }^{1}$, rajes.aravind@gmail.com ${ }^{2}$
}

\begin{abstract}
The word "lattice" is meant by the repetition of a geometrical structure, arranged in regular fashion over entire object. The lattice structure was used in aerospace and defense fields due to its high strength to weight ratio and other improved mechanical properties. In the present work, an attempt is made to model, analyse and compare the mechanical properties of three different lattice structures of different configurations. For this work, the Body centered cubic structure is modified to create cubic lattice having its corners of top face attached to the Centre of bottom face with and without vertical supports. Double pyramid lattice structure with cross is also selected for comparison with the above two modified lattice structures. Finite element modeling approach is used to determine the load-displacement as well as stress-strain of all the three configurations under quasi-static compression. The structures are designed and analyzed using Solidworks and ANSYS software. The mechanical properties are to be compared. The result shall show that the modified bcc structure has reduced deflection and increased compressive strength than conventional BCC lattice structure. Models were prepared by fused deposition modeling (FDM) 3D printer.
\end{abstract}

Index Terms-Lattice structure; Modified BCC; fused deposition modeling

\section{INTRODUCTION}

In general, lightweight materials were used in aerospace and automobile industries for better performance. We can obtain light weight by eliminating the unwanted mass without disturbing the original strength. One of the techniques majorly used in industries for mass removal is mass decompounding. By eliminating unwanted mass, strength may decrease. Hence internal lattice structures were used instead of solid structure to obtain better strength and stiffness to weight ratio. Cellular lattice structures contain 3 parallel intersectional planes, fabricated using FDM with six faces. Each face is organized in sets of parallel planes, therefore creating a parallelepiped[1]. Struts are used as interconnections between the planes. Many complex geometry is usually fabricated through additive manufacturing. Here these structures were manufactured using fused deposition modeling printer. Subtractive manufacturing is quite complex and time consuming while producing the lattice structures[2].

Here, three types of modified Body centered cubic lattice structures with corners of top face attached to the center of bottom face with and without vertical supports were designed and manufactured. Double pyramid lattice structure with cross. For all types, the strut diameter will be adjusted within the unit cell to yield different weight and mass reduction from a solid 8.5 cubic millimeter. Lattice structures possess high strength-to-weight magnitude than that of solid materials [3]. In this work, the ratio between stiffness and weight, and effective modulus-to-weight ratio in all the three the Cubic lattice with Bottom Centre without Vertical Support, Cubic Lattice with Bottom Centre with Vertical Support and Pyramid Lattice with Cross specimens with varying strut diameters were analyzed.

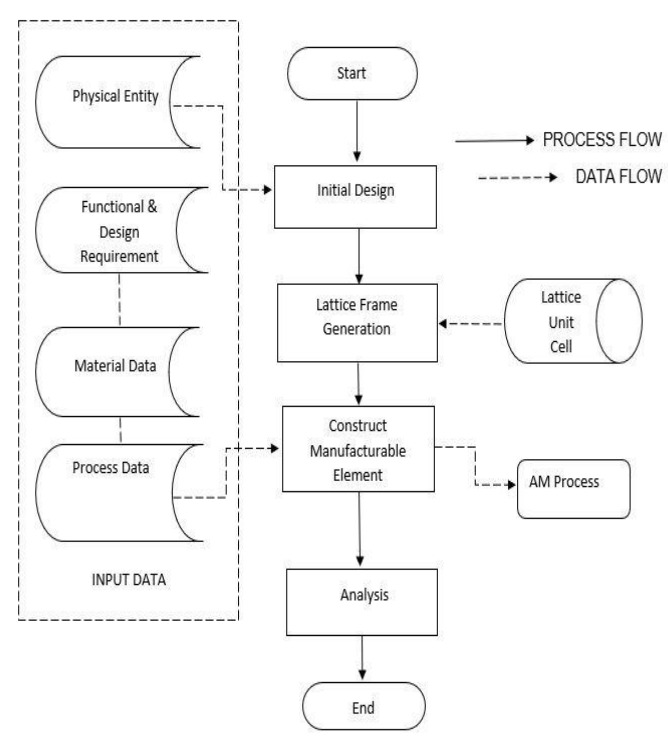

Fig 1. Flow chart

\section{UNIT CELL DESIGN}

For this study, three different topologies were used: Cube Lattice with Bottom Centre without Vertical Support, Cube Lattice with Bottom Centre with Vertical Support, Pyramid Lattice with Cross. Each 
specimen lattice was contained within 8.5 x 8.5 x 8.5 $\mathrm{mm}^{3}$ [4]. The Cube Lattice with Bottom Centre Vertical Support consist of struts cubic lattice having its corners of top face attached to the Centre of bottom face with vertical supports. the internal volume of the cube vacant [5]. The Cube Lattice with Bottom Centre Without Vertical Support consist of struts cubic lattice having its corners of top face attached to the Centre of bottom face without vertical supports, the cube vacant. another unit cell totally different from BCC lattice unit cell, its double pyramid with cross center of unit cell having strut joint [6], all lattice specimen was modeled in SOLIDWORKS. Each topology's strut diameters were adjusted to yield certain weight drops from a solid $\quad 8.5 \times 8.5 \times 8.5$ cubic millimeter, ranging from approximately $55 \%$ reduction to $90 \%$ reduction. Three types of specimen strut geometry were tested with all strut diameters uniform per specimen.

\section{LATTICE STRUCTURE}

Three types of unit cell change strut geometry and each of unit cell is converted to lattice structure with help of the linear pattern tool in solid works, pattern do in three coordinate system like $\mathrm{x}, \mathrm{y}, \mathrm{z}$, then convert all the unit cell in a single $3 \times 3 \times 3$ lattice structure. Each lattice structure having six different diameters of strut in $3 \times 3 \times 3$ lattice structure. Strut Diameter 1.5, 2, 3, 4, 4.5, $5 \mathrm{~mm}$

\subsection{Material property}

Titanium Alloys - Ti6Al4V Grade 5

\begin{tabular}{|l|l|}
\hline Density & $4.512 \mathrm{~g} / \mathrm{mm}^{3}$ \\
\hline Bulk modulus & $153 \mathrm{GPa}$ \\
\hline Compressive strength & $1080 \mathrm{MPa}$ \\
\hline Elastic limit & $910 \mathrm{MPa}$ \\
\hline Poisson ratio & 0.37 \\
\hline Tensile strength & $1200 \mathrm{MPa}$ \\
\hline Young's modulus & $119 \mathrm{GPa}$ \\
\hline
\end{tabular}

\section{ANSYS}

ANSYS could be a general software package, to analyze the parameters corresponding to physics, structural vibration, dynamics characteristics of fluid and heat flow for engineers. ANSYS will import CAD information and additionally allows to create a pure mathematics with its pre-processing talents. ANSYS will accomplish advanced engineering analyses in quick manner. Their results were closely related to the practical testing conditions. ANSYS workbench integrates simulation technologies and constant quantity CAD systems with distinctive automation and performance.

\subsection{Finite element analysis}

This final FEA was performed after some preliminary testing $5 \mathrm{KN}$ to $40 \mathrm{KN}$ and $40 \mathrm{kN}$ was chosen so that each analysis was testing within the elastic region [7]. The load was also chosen due to the FEA being performed in SOLIDWORKS being a linear, static analysis so remaining within the elastic region of the model is imperative. The mesh used in this analysis was a curvature-based mesh, with a maximum and minimum element size of $0.858 \mathrm{~mm}$ and $0.043 \mathrm{~mm}$ respectively. The displacement results from the FEA were analyzed and the highest displacement result per simulation was used to calculate the specimen's stiffness [8]. This is due to all the displacement being within the lattice model. Now knowing force and displacement for each specimen, the stiffness can be calculated using

Where,

$$
k=\frac{F}{d}
$$

$\mathrm{F}$ is the force applied, $\mathrm{d}$ is the displacement result in each FEA performed in compression.

\section{RESULTS}

Thus the 3-dimensional lattice structures are created and analyzed with the existing one. Three different lattice structures such as cube lattice with bottom centre without vertical support, cube lattice with bottom centre with vertical support and double pyramid lattice with cross was created using SOLIDWORKS. The compared to existing structure (BCC lattice structure) with various parameters and based on the results obtained the best structure is identified among the 4 structures. Each structure is analysed with 6 various strut diameters, so totally 24 different specimens were analysed. Initially different loads are applied on structures and analysed for deformation. The best structure is obtained by comparing all structures with respect to stiffness to weight ratio at constant load of $40 \mathrm{KN}$.

Following FEA results represents samples from 1 to 4, total deformation for Various strut diameter such as $1.5 \mathrm{~mm}, 2 \mathrm{~mm}, 3 \mathrm{~mm}, 4 \mathrm{~mm}, 4.5 \mathrm{~mm}, 5 \mathrm{~mm}$. load to applied is $5 \mathrm{KN}$ to $40 \mathrm{KN}$.

Sample 1 - Cube lattice with bottom centre with vertical support

Sample 2 - Cube lattice with bottom centre without vertical support

Sample 3 - Double pyramid lattice structure with cross

Sample 4 - Body-centered cube (BCC)

The sample 4 is the existing body centred cubic structure and remaining structures are newly designed and analysed with the existing one.The total deformation of cubic lattice structure with bottom centered vertical support were analyzed using ANSYS and the corresponding results were shown in following fig 2 . 


\section{Available online at www.ijrat.org}

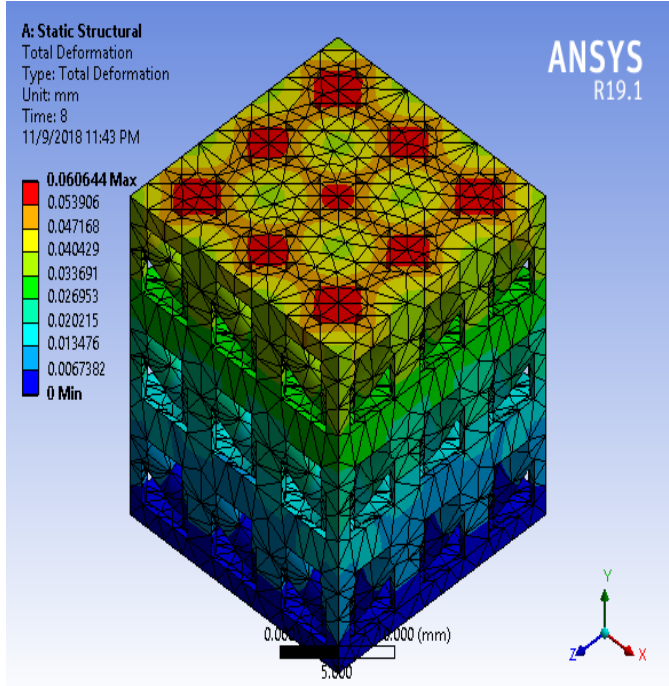

Fig 2. Total deformation of Cube lattice with bottom centre with vertical support (diameter-3 $\mathrm{mm})$

The total deformation of cubic lattice structure with crossed double pyramid structure were analyzed using ANSYS and the corresponding results were shown in following fig. 3

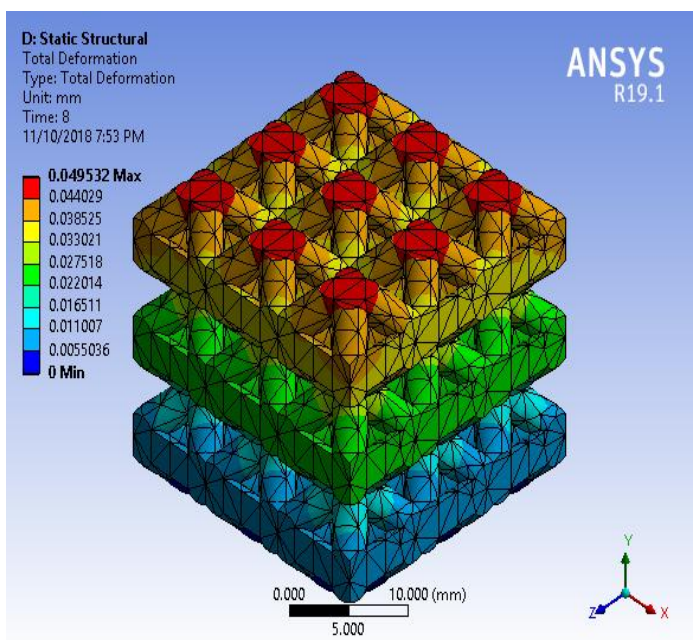

Fig 3. Total deformation of Double pyramid lattice structure with cross (diameter $-3 \mathrm{~mm}$ )

The total deformation of cubic lattice structure with bottom centered without support were analyzed using ANSYS and the corresponding results were shown in following fig. 4

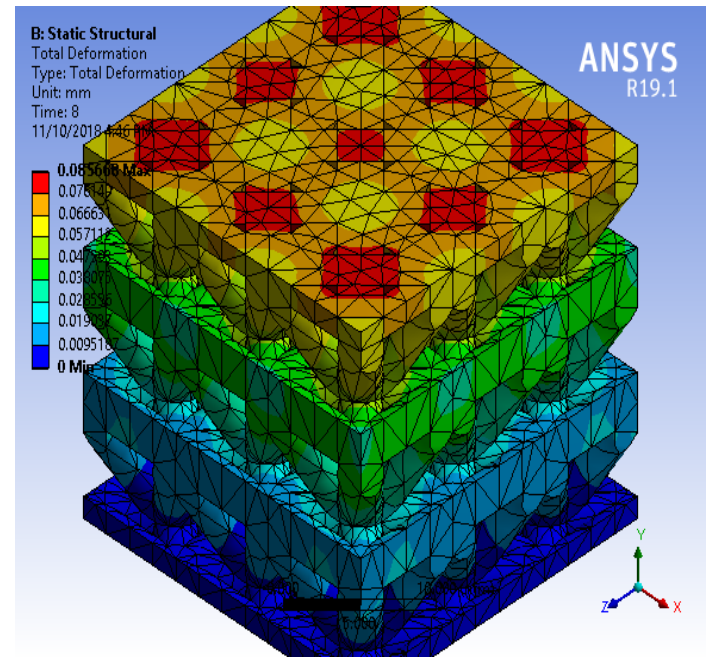

Fig 4. Total deformation of Cube lattice with bottom center without vertical support (diameter$3 \mathrm{~mm})$

The total deformation of actual BCC cubic lattice structure were analyzed using ANSYS and the corresponding results were shown in following fig.5

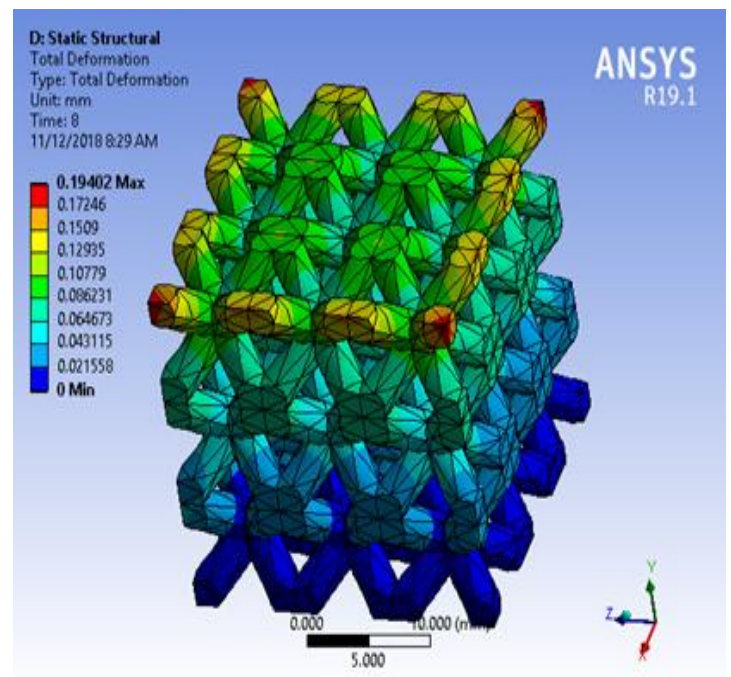

Fig 5. Total deformation of Body-centered cube (BCC) existing one (diameter $-3 \mathrm{~mm}$ )

The following fig. 6 shows the load vs deflection curve for various diameter of sample 1where green represents sample with strut diameter $1.5 \mathrm{~mm}$, blue line represents sample with strut diameter $2 \mathrm{~mm}$, yellow line represents the sample with strut diameter 3 $\mathrm{mm}$, black line represents the sample with strut diameter $4 \mathrm{~mm}$, brown line represents the sample with strut diameter $\quad 5 \mathrm{~mm}$.these color lines are same for other samples also. 
International Journal of Research in Advent Technology, Vol.7, No.4, April 2019

E-ISSN: 2321-9637

Available online at www.ijrat.org

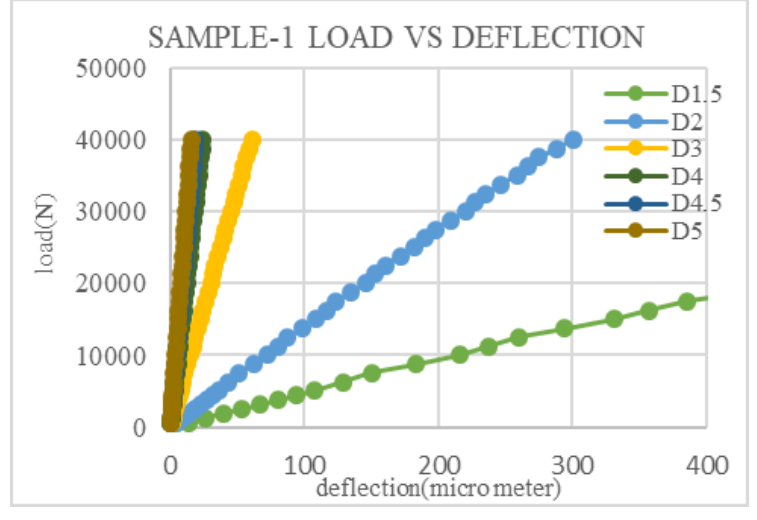

Fig 6. Comparison between load and deflection for sample 1

The following fig. 7 shows the load vs deflection curve for sample 2 with varying strut diameter

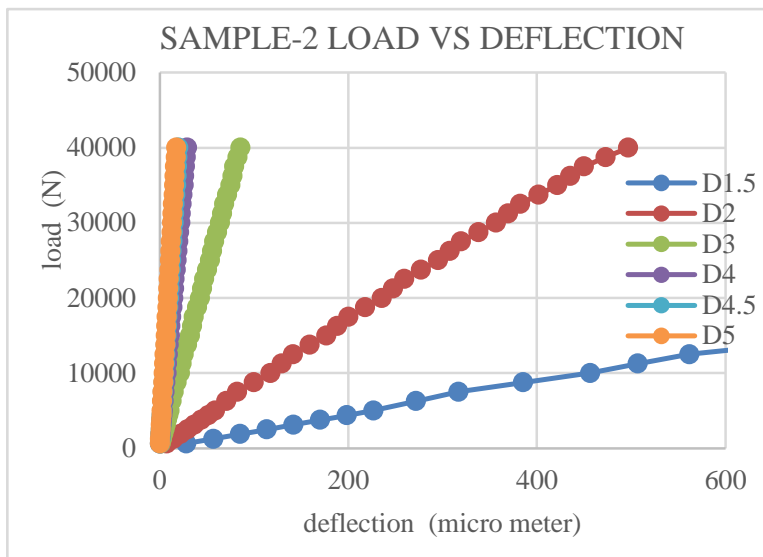

Fig 7.Comparison between load and deflection for sample 2

The following fig. 8 shows the load vs deflection curve for sample 3 with varying strut diameter

\section{SAMPLE-3 LOAD VS DEFLECTION}

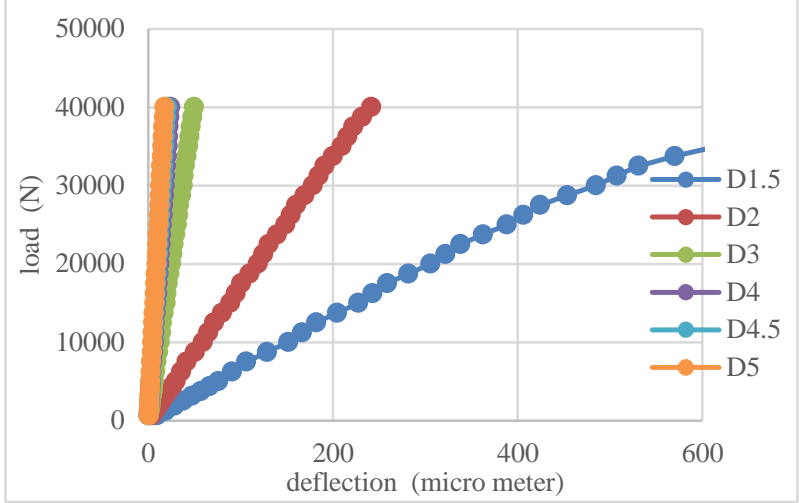

Fig 8. comparison between load and deflection for sample 3

The following fig.9 shows the load vs deflection curve of sample 3 with varying strut diameter

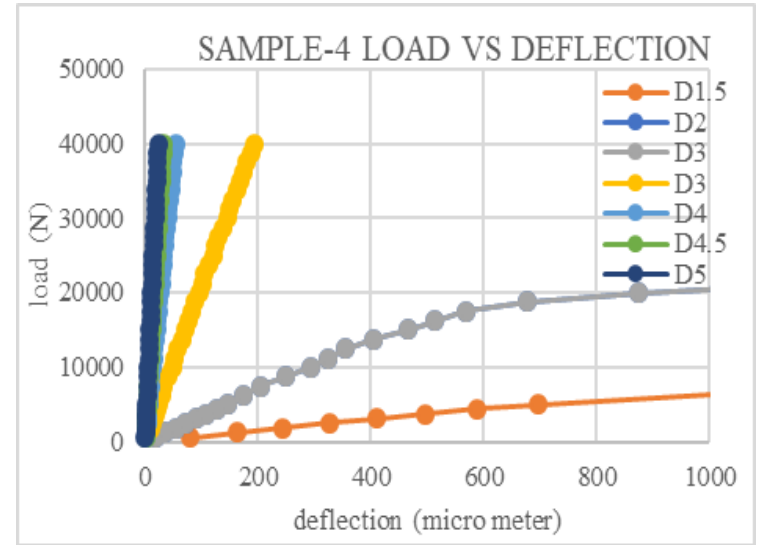

Fig 9.Comparison between load and deflection for sample 4

The following fig.10 represents stiffness to weight ratio corresponding to varying diameter for different samples

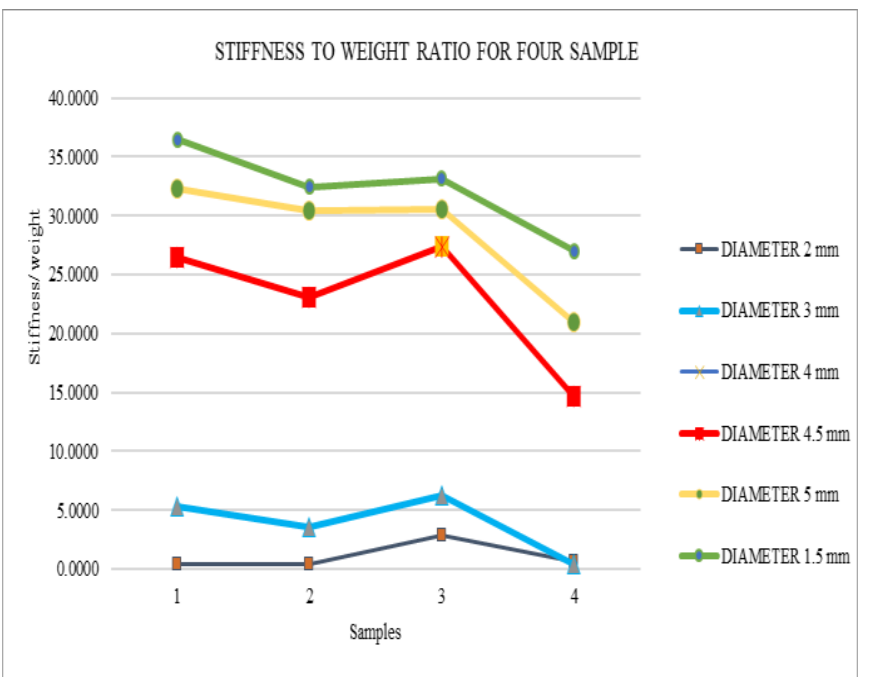

Fig 10.Comparison between stiffness to weight for various samples

The table 1. Represents the various parameters such as strut diameter, mass and deflection for various samples at varying diameters.

Here sample 1 represents Cube Lattice with Bottom Centre With Vertical Support.

Sample 2 represents Cube Lattice without Bottom Centre with Vertical Support.

Sample 3 represents Pyramid Lattice with Cross. Whereas sample 4 represents Bottom Center Cube. 
Table 1. Deflections for different samples under various conditions

\begin{tabular}{|c|c|c|c|}
\hline Sample & $\begin{array}{l}\text { Strut } \\
\text { diameter } \\
(\mathrm{mm})\end{array}$ & $\begin{array}{l}\text { Mass } \\
\text { (grams) }\end{array}$ & Deflection $(\mu \mathrm{m})$ \\
\hline \multirow{6}{*}{1} & 1.5 & 15.185 & 6365.7 \\
\hline & 2 & 24.686 & 301.16 \\
\hline & 3 & 45.151 & 60.644 \\
\hline & 4 & 61.955 & 24.355 \\
\hline & 4.5 & 67.404 & 18.39 \\
\hline & 5 & 70.04 & 15.649 \\
\hline \multirow{6}{*}{2} & 1.5 & 13.933 & 5966.9 \\
\hline & 2 & 22.786 & 497.09 \\
\hline & 3 & 42.375 & 85.668 \\
\hline & 4 & 59.629 & 29.081 \\
\hline & 4.5 & 65.994 & 19.89 \\
\hline & 5 & 69.916 & 17.629 \\
\hline \multirow{6}{*}{3} & 1.5 & 16.267 & 850.17 \\
\hline & 2 & 26.183 & 241.19 \\
\hline & 3 & 46.56 & 49.532 \\
\hline & 4 & 61.136 & 23.895 \\
\hline & 4.5 & 65.659 & 19.934 \\
\hline & 5 & 68.962 & 17.485 \\
\hline \multirow{6}{*}{4} & 1.5 & 10.361 & 6027.4 \\
\hline & 2 & 17.263 & 5671.8 \\
\hline & 3 & 33.64 & 194.02 \\
\hline & 4 & 50.555 & 53.984 \\
\hline & 4.5 & 58.131 & 32.876 \\
\hline & 5 & 64.5 & 22.955 \\
\hline
\end{tabular}

The table 2. Represents the various parameters such as strut diameter ,mass and deflection for various samples at varying diameters.

From the table for sample 1 with the corresponding strut weight without disturbing stiffness. The optimum structure will be of smaller diameter corresponds to optimum deflection. Thus the samples with strut diameter $3 \mathrm{~mm}$ posses optimum deflection with minimal weight. Among these four samples of $3 \mathrm{~mm}$ strut diameter, the best structure is sample 3 with strut diameter of $3 \mathrm{~mm}$ under loading conditions.

Table 2. stiffness to weight ratio for different samples under various conditions

\begin{tabular}{|c|c|c|}
\hline Sample & $\begin{array}{l}\text { Stiffness } \\
(\mathrm{KN} / \mathrm{mm})\end{array}$ & $\begin{array}{l}\text { Stiffness to } \\
\text { Weight ratio } \\
(\text { KN/N mm) }\end{array}$ \\
\hline \multirow{6}{*}{1} & 6 & 0.3951 \\
\hline & 132 & 0.4306 \\
\hline & 659 & 2.8893 \\
\hline & 1642 & 0.5791 \\
\hline & 2175 & 5.3472 \\
\hline & 2556 & 3.5109 \\
\hline \multirow{6}{*}{2} & 6 & 6.3018 \\
\hline & 80 & 0.4055 \\
\hline & 466 & 14.5955 \\
\hline & 1375 & 10.9971 \\
\hline & 2011 & 17.3325 \\
\hline & 2268 & 6.1237 \\
\hline \multirow{6}{*}{3} & 47 & 26.5031 \\
\hline & 165 & 23.0592 \\
\hline & 807 & 27.3652 \\
\hline & 1673 & 14.6375 \\
\hline & 2006 & 32.2681 \\
\hline & 2287 & 30.4725 \\
\hline \multirow{6}{*}{4} & 6 & 30.5518 \\
\hline & 7 & 20.9183 \\
\hline & 206 & 36.4934 \\
\hline & 740 & 32.4389 \\
\hline & 1216 & 33.1632 \\
\hline & 1742 & 27.0078 \\
\hline
\end{tabular}

\section{CONCLUSION}

Lattice structures offer a great opportunity for light weight applications and energy absorbers. The designed lattice structures were analyzed. It is observed that the mechanical behavior and mechanism of failure for lattice structures were highly dependent on the type and dimension of the unit cells out of diahietethe rtanoipossesstminime mataflechion the conispiargd to other sample and developed lattice structures analyzed using ANSYS software by static analysis. In this work, 24 samples have been analyzed for different parameters such as stiffness, deflection and proportion between stiffness and weight under the different loads.

The developed models shown higher strength and stiffness and deform at lesser rate as compared to existing one. The samples possess higher compressive load bearing capacity than the existing model. Loading was carried more uniformly in the entire $3 \times 3 \times 3$ structure rather than being highly concentrated at the connection locations. The developed cube lattice with bottom centre with vertical support is 3.2 times better than the existing model. Likewise, the cube lattice with bottom centre without vertical support and double pyramid lattice with cross are 2.26 times and 3.92 times better than the existing model. Thus, the double pyramid lattice with cross is the best structure with respect to the compressive load. 


\section{REFERENCES}

[1] S. Jamian, M. R. Zainal Abidin, and A. M. Muda, "Crashworthiness behavior of hollow Al-Based functionally graded material (FGM) Box under box under quasi-static loading," Appl. Mech. Mater., vol. 773-774, pp. 110-114, 2015.

[2] S. Mohsenizadeh, R. Alipour, A. F. Nejad, M. S. $\mathrm{Rad}$, and Z. Ahmad, "Experimental Investigation on Energy Absorption of Auxetic Foam-filled Thinwalled Square Tubes under Quasi-static Loading," Procedia Manuf., vol. 2, February, pp. 331-336, 2015. [3] E. S. G. Maliaris, "Mechanical behavior of 3D printed stochastic lattice structures," October, pp. 0-4, 2016.

[4] H. D. Carlton et al., "Mapping local deformation behavior in single cell metal lattice structures," Acta Mater., vol. 129, pp. 239-250, 2017.

[5] S. Merkt, C. Hinke, J. Bültmann, M. Brandt, and Y. M. Xie, "Mechanical response of TiAl6V4 lattice structures manufactured by selective laser melting in quasistatic and dynamic compression tests," J. Laser Appl., vol. 27, S17006, 2015.

[6] D. J. Sypeck and H. N. G. Wadley, "Cellular metal truss core sandwich structures," Adv. Eng. Mater., vol. 4, pp. 759-764, 2002.

[7] Jason Nguyen, Sang-In Park, David W. Rosen, Luis Folgar, James Williams," Conformal Lattice Structure Design and Fabrication" School of Mechanical Engineering. Georgia Institute of Technology Paramount Industries, a 3D Systems Company.

[8] Maskery, A.O. Aremu, L. Parry, R.D. Wildman, C.J. Tuck, I.A. Ashcroft "Effective design and simulation of surface-based lattice structures featuring volume fraction and cell type grading" pp. 220232,2018.

[9] I. Maskery, N.T. Aboulkhair, A.O. Aremu, C.J. Tuck, I.A. Ashcroft "Compressive failure modes and energy absorption in additively manufactured double gyroid lattices" Additive Manufacturing, pp.24-29, 2017.

[10] L. Boniotti , S. Beretta , S.Foletti, L.Patriarca "Strain Concentrations In BCC micro lattice obtained by AM” Procedia Structural Integrity 7,166-173, 2017 [11] R Umer, Z Barsoum, HZ Jishi, K Ushijima and WJ Cantwell "Analysis of the compression behaviourof different composite lattice designs" Journal of Composite Materials, Vol. 52, pp.715-729, 2018.

[12] L. Junyi , D.S. Balint "A parametric study of the mechanical and dispersion properties of cubic lattice structures" International Journal of Solids and Structures,pp.55-71, 2016

[13] Shanqing $\mathrm{Xu}$, Jianhu Shen, Shiwei Zhou, Xiaodong Huang, Yi Min Xie "Design of lattice structures with controlled anisotropy" Materials and Design pp.443-447,2016.

[14] S. Bernard, Q. Grimal, P. Laugier, "Accurate measurement of cortical bone elasticity tensor with resonant ultrasound spectroscopy", J. Mech. Behav. Biomed.pp.12-19,2013.

[15] V.J. Challis, A.P. Roberts, J.F. Grotowski, L.C. Zhang, T.B. Sercombe, "Prototypes for bone implant scaffolds designed via topology optimization and manufactured by solid freeform fabrication", Adv. Eng. Mater. 12 pp.1106-1110, 2010. 